\title{
Isolation of Uranium by Anionic Exchange Resins
}

\author{
Fabiola Monroy-Guzmán ${ }^{*}$ \\ Instituto Nacional de Investigaciones Nucleares, Carretera México-Toluca S/N 52750, Mexico
}

\begin{abstract}
A separation methodology to isolate natural uranium from its radioactive daughters: Th, $\mathrm{Ra}, \mathrm{Bi}, \mathrm{Pb}, \mathrm{Pa}$ and $\mathrm{Po}$, was developed using an only one anion exchange resin and varying concentrations of $\mathrm{HCl}$ solutions. Three types of anion exchange resins were tested and the separation process was followed by gamma and alpha spectrometry. Uranium can be quantitatively isolated from its descendants using Dowex 1X8 (20-50 mesh) or Amerlite IRA (100 mesh) resins in three steps: using 4 and $8 \mathrm{~mol} / \mathrm{L}^{-1} \mathrm{HCl}$ and water to recover uranium. The method is easy, quick, and inexpensive.
\end{abstract}

Key words: Anion exchange resin, uranium, separation.

\section{Introduction}

Detection and quantification of uranium isotopes from its radioactive daughters (Th-234, Pa-234, Ra-226, Po-218, Pb-214, Bi-214, Pb-210, Bi-210, $\mathrm{Po}-210$, and $\mathrm{Pb}$ 206) are essential in applications such as nuclear fuel cycle, geological research (oceanography, paleoclimatology, and volcanology), environmental isotope studies, characterization of radioactive waste, and so on [1-5].

Natural uranium has three radioisotopes: U-238 (99.284\%), U-235 (0.711\%), and U-234 (0.0085\%) that can be identified and quantified by alpha spectrometry once the uranium has been purified of its descendants. The most common techniques used for the separation and purification of uranium include co-precipitation, solvent extraction, ion exchange resins, and chromatographic extraction. Organic acids, ketones, ethers, esters, alcohols, and organic phosphates have been used in the extraction of uranium and other actinides [6-7]. In particular, methyl isobutyl ketone has been used extensively in the extraction of $\mathrm{U}$ and $\mathrm{Pu}$ from spent nuclear fuel.

Ion exchange chromatography is one of the most popular methods to separate and isolate metals,

\footnotetext{
*Corresponding author: Fabiola Monroy-Guzman, Ph.D., research fields: radiochemistry and radioactive waste management.
}

because of its high degree of selectivity, reversibility, short separation times, and so on [6-8]. In particular, anion-exchange resins have been widely used for uranium separation [6, 7, 9-11]. For example, Junten et al. reported the separation of uranium, thorium, and radium from rock samples using an anion-exchange column: The rock is dissolved in acid and added to an anion-exchange column that is pretreated with $9 \mathrm{~mol} / \mathrm{L}^{-1}$ $\mathrm{HCl}$. The uranium is retained on the exchanger as a negative uranium chloride complex, while thorium and radium, which do not form chloride complexes, pass through the column. Uranium is then eluted from the column, which causes the uranium chloride complexes to break down, and the uranium elutes in cationic form. Alhassanieh et al. [7, 10] reported the separation of $\mathrm{U}, \mathrm{Th}, \mathrm{Pa}$, and $\mathrm{Ra}$ from the natural uranium series $(4 n+2)$ by first using an anion-exchange resin in $\mathrm{HCl}$ medium to adsorb $\mathrm{U}$ and $\mathrm{Pa}$. $\mathrm{U}$ is eluted after 2 days once $\mathrm{Pa}-234$ has decayed. Th and $\mathrm{Ra}$ are separated by the cation exchange resin in $\mathrm{HNO}_{3}$, since Th is adsorbed and $\mathrm{Ra}$ is eluted. Crespo et al. [12] performed the separation of Ra, U, Th and Pa from geological samples using three chromatography columns. First uranium is retained in an anion-exchange resin (Dowex 1X8, 200 mesh) column in $9 \mathrm{~mol} / \mathrm{L}^{-1} \mathrm{HCl}$ and the thorium recovered in the eluted solution. Thorium is then adsorbed in a other anion-exchange resin in $8 \mathrm{~mol} / \mathrm{L}^{-1} \mathrm{HNO}_{3}$, while the 
radium contained in the eluate of this second column is purified in a cation-exchange resin (Dowex 50W-X8, 100 mesh) at $\mathrm{pH} 1$ [13].

Solid-phase extraction, in combination with an ion exchanging, has also been used in the separation of $U$ from its radioactive daughters. For example, Koornneef et al. used a TRU spec column and a cation-exchange resin to separate $\mathrm{Ra}, \mathrm{U}, \mathrm{Th}$, and $\mathrm{Pa}$ from volcanic rocks. The method begins with the elution of Ra and most other matrix elements, such as alkalis, alkali earths, transition metals, and heavier lanthanides, using a TRU spec column conditioned in $4 \mathrm{~N} \mathrm{HCl}$. Subsequently, Th is eluted in $0.8 \mathrm{~N} \mathrm{HCl}$, following consecutive elution of U-Pa with $0.1 \mathrm{~N}$ $\mathrm{HCl} / \mathrm{HF}$. The TRU-spec resin is discarded after use, and the U-Pa fraction is evaporated and dissolved in 1 $\mathrm{N} \mathrm{HCl}+0.01 \mathrm{~N} \mathrm{HF}$ and loaded onto a BioRad AG50-X8 column that separated Pa from U. Rožmarić et al. [11] carried out the isolation of $U$ and $T h$ from natural samples using UTEVA and TRU Eichrom ${ }^{\circledR}$ resins in combination with and anion exchanger. They developed two methods: in the first one, $\mathrm{U}$ and $\mathrm{Th}$ contained in samples of drinking water and seawater were loaded on columns filled with TRU Eichrom ${ }^{\circledR}$ resin. Thorium was then separated from the $U$ with $0.5 \mathrm{~mol} / \mathrm{L}^{-1} \mathrm{HCl}$, and the $\mathrm{U}$ was eluted with deionized water. In the second method, $\mathrm{U}$ and $\mathrm{Th}$ were isolated from the soil samples with TRU resin while they were separated from each other on the column and filled with anion exchanger in alcohol solutions [14].

Ion exchangers have been used mainly in the separation of U-Th-Ra. Therefore, the aim of this work is to develop a method of uranium separation from its radioactive daughters thorium, radium, protactinium, lead, bismuth and polonium quickly and efficiently, using only anion exchangers and $\mathrm{HCl}$ solutions. Thus, the authors studied the effect of the anion exchanger type used and the particle size of the exchanger in the separation performance.

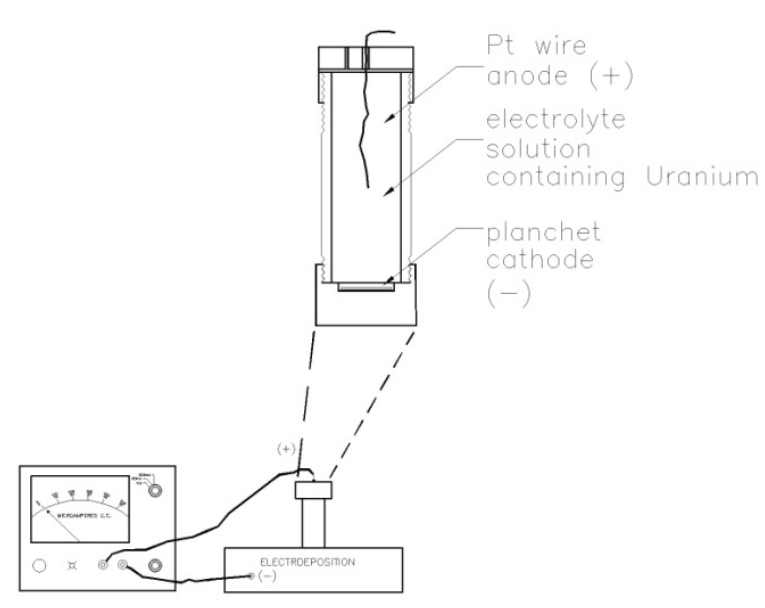

Fig. 1 Set-up for the electrodeposition.

\section{Experiments}

According to the literature, the adsorption properties of $\mathrm{U}, \mathrm{Th}, \mathrm{Pa}, \mathrm{Ra}, \mathrm{Pb}, \mathrm{Bi}$, and $\mathrm{Po}$ on anion exchange resins in a hydrochloric acid medium are as follows: Radium and thorium are not adsorbed. Protactinium and uranium are weakly adsorbed at lower concentrations up to $1 \mathrm{M}$ and increase their retention with an increase in $\mathrm{HCl}$ concentration. Bismuth is strongly adsorbed between 0 and $12 \mathrm{M}$ $\mathrm{HCl}$. Lead is weakly adsorbed between 0 and $7 \mathrm{M} \mathrm{HCl}$, and concentrations higher than $7 \mathrm{M}$ are not adsorbed on the resin [6]. Therefore, the general methodology of uranium purification proposed in this work is based on these adsorption properties, which include the following stages: 1) evaporation of uranium sample; 2) recovery of uranium in about $300 \mu \mathrm{L}$ of $4 \mathrm{M} \mathrm{HCl}$; 3) application of uranium sample to chromatography system packed with the anion exchange resin previously pre-equilibrated in $4 \mathrm{M} \mathrm{HCl}$; 4) elution with $4 \mathrm{M} \mathrm{HCl}$; 5) elution with $8 \mathrm{M} \mathrm{HCl}$; and 6) wash with distilled water.

Amerlite ${ }^{\circledR}$ IRA-Cl, 100 mesh; Dowex 1X8, 20-50 mesh; and Dowex 1X8, 200 mesh anion exchange resins were evaluated in this work. A $0.21 \mathrm{M}$ uranyl nitrate $\left[\mathrm{UO}_{2}\left(\mathrm{NO}_{3}\right)_{2}\right]$ solution was evaporated to dry on a heating plate and recovered in around $300 \mu \mathrm{L}$ of $4 \mathrm{M}$ $\mathrm{HCl}$. The solution was loaded into Poly-Prep ${ }^{\circledR}$ Bio Rad chromatographic columns $(0.8 \times 4 \mathrm{~cm})$ packed 
with the anion exchange resin previously equilibrated in $4 \mathrm{M} \mathrm{HCl}$, and then the process of six stages described previously was applied. The separation process was followed by a gamma spectrometry system, constituted by a coaxial GeHp CANBERRA detector connected to a CANBERRA 2002CSL preamplifier, a CANBERRA high-voltage power supply model 3105, a Tennelec TC 243 amplifier, and a CANBERRA multichannel analyzer supported by Genie ${ }^{\mathrm{TM}} 2000$ software. Ra-226, Pa-234, Th-234, Bi-214 and Pb-214 were used as radioisotope indicators of the separation process (Table 1). All eluates were quantified for $7,200 \mathrm{~s}$ at the same geometry.

In order to verify the purity of uranium recovered in the last eluate from the separation process, which contains uranium, the eluate was evaporated and recovered in $0.5 \mathrm{M} \mathrm{NaF}$. Some drops of $0.1 \%$ phenolphthalein in ethanol were added to this solution and then the $\mathrm{pH}$ was adjusted to 9 with $5 \mathrm{M} \mathrm{NaOH}$ [15]. The solution was finally transferred into the electrodeposition cell (Fig. 1), composed of a mirror-polished stainless steel disc $4 \mathrm{~cm}$ in diameter, which acted as cathode in the electrolytic system, and an anode comprised of a platinum wire $1 \mathrm{~mm}$ in diameter and $10 \mathrm{~cm}$ long. The distance between the platinum anode and the stainless steel backing cathode was set between $0.5-1 \mathrm{~cm}$. The electrodeposition cell was disassembled (Fig. 1), and the electrodeposition process was performed at $10 \mathrm{~mA}$ current for $6 \mathrm{~h}$ [15]. Finally, the backing was raised with acetone and then heated on a hot plate in order to fix the deposited $U$.

Analysis of the purified uranium was conducted using alpha spectrometry in an ORTEC 576A Dual Alpha brand spectrometer, comprising two surface barrier detectors with an active area of $300 \mathrm{~mm}^{2}$. The distance from the source to detector was $1 \mathrm{~cm}$. The sample and detector were housed in a cylindrical aluminum chamber weighing less than 30 torr in a vacuum. The spectrometer was connected to a multichannel buffer ORTEC 920E, and spectral analysis was performed using ORTEC Alpha Vision 3.2 software.

\section{Results and Discussions}

Table 2 shows the recovery percentage of uranium and its radioactive descendants in the separation process proposed.

Table 1 Gamma properties of the uranium descendants used in the purification process.

\begin{tabular}{llll}
\hline Radioisotope & E $\gamma(\mathrm{keV})$ & Half-life & $\mathrm{I} \gamma(\%)$ \\
${ }^{234} \mathrm{Th}$ & 92.35 & $24.1 \mathrm{~d}$ & 2.5 \\
${ }^{234} \mathrm{~Pa}$ & 130 & $6.7 \mathrm{~h}$ & 20 \\
${ }^{226} \mathrm{Ra}$ & 946 & & 20 \\
${ }^{214} \mathrm{~Pb}$ & 186 & $1600 \mathrm{a}$ & 3.28 \\
${ }^{214} \mathrm{Bi}$ & 352 & $26.8 \mathrm{~min}$ & 37 \\
\hline
\end{tabular}

Table 2 Recovery percentages of metals in uranium samples using anionic-exchange resins.

\begin{tabular}{lllll}
\hline \multicolumn{3}{c}{ Recovery } \\
\hline Eluant & Element & $\begin{array}{l}\text { DOWEX 1X8 } \\
20-50 \text { mesh }\end{array}$ & $\begin{array}{l}\text { Amerlite Ira } \\
100 \text { mesh }\end{array}$ & $\begin{array}{l}\text { DOWEX 1X8 } \\
200 \text { mesh }\end{array}$ \\
\hline $4 \mathrm{M} \mathrm{HCl}$ & $\mathrm{Th}$ & $99.2 \%$ & $95.9 \%$ & $99.6 \%$ \\
$4 \mathrm{M} \mathrm{HCl}$ & $\mathrm{Ra}$ & $78 \%$ & $69.1 \%$ & $5.9 \%$ \\
$4 \mathrm{M} \mathrm{HCl}$ & $\mathrm{Pa}$ & $88.8 \%$ & $61.5 \%$ & $66.5 \%$ \\
$8 \mathrm{M} \mathrm{HCl}$ & $\mathrm{Pb}$ & $>99 \%$ & $>99 \%$ & $>99 \%$ \\
$\mathrm{H}_{2} \mathrm{O}$ & $\mathrm{U}$ & $>99 \%$ & $>99 \%$ & $>99 \%$ \\
$\mathrm{H}_{2} \mathrm{O}$ & $\mathrm{Bi}$ & $<0.1 \%$ & $<0.1 \%$ & $<0.1 \%$ \\
$\mathrm{H}_{2} \mathrm{O}$ & $\mathrm{Po}$ & $<0.1 \%$ & $<0.1 \%$ & $<0.1 \%$ \\
\hline
\end{tabular}




\subsection{At $4 \mathrm{M} \mathrm{HCl}$}

The thorium $\left(\mathrm{Th}^{4+}\right)$ is eluted quantitatively $(>95 \%)$ in any of the studied anionic resins, because it does not form anionic chloride complexes and is not retained in strongly basic anion-exchange resins [16].

In the case of protactinium, $88 \%$ of $\mathrm{Pa}^{5+}$ pass through the column loaded with DOWEX 1X8 20-50 mesh and around of $61 \%$ with IRA AMERLITE and DOWEX 1X8 200 mesh. The predominant species of protactinium (V) in $\mathrm{HCl}$ reported in the literature are as follows: $<1 \mathrm{M} \mathrm{PaO}(\mathrm{OH})^{2+}, 2 \mathrm{M} \mathrm{PaOOHCl}^{+}, 3 \mathrm{M}$ $\mathrm{PaOOHCl}_{2}$ or $\mathrm{PaOCl}_{3}$ or $\mathrm{PaO}_{2} \mathrm{Cl}_{2}^{-}, 4 \mathrm{M} \mathrm{PaO}^{3+}$ or $\mathrm{PaOOHCl}_{3}{ }^{-}, 5 \mathrm{M} \mathrm{PaOCl}_{4}^{-}, 6 \mathrm{M} \mathrm{PaOCl}_{5}{ }^{2-}$ or $\mathrm{PaOHCl}_{6}{ }^{2-}$, $7 \mathrm{M} \mathrm{PaCl}_{6}{ }^{-}, 8 \mathrm{M} \mathrm{PaCl}_{7}{ }^{2-}$, and $9 \mathrm{M} \mathrm{PaCl}_{8}{ }^{3-}$ or $\mathrm{PaOCl}_{6}{ }^{3-}$ $[16,17]$. The presence of the anionic species, $\mathrm{PaOOHCl}_{3}^{-}$at $4 \mathrm{M} \mathrm{HCl}$, explains the fact that a percentage of $\mathrm{Pa}(\mathrm{V})$ stays adsorbed on the anionic resin ; while the particle size of the resin justifies the differences in the percentage of $\mathrm{Pa}(\mathrm{V})$ eluted (Table 2). A smaller particle size of the anion resin produces a larger adsorption surface area, and therefore, a higher percentage of anions can be adsorbed on the resin. Thus, it is better to use the DOWEX 1X8 20-50 mesh resin to recover $\mathrm{Pa}$.

Radium $\left(\mathrm{Ra}^{2+}\right)$ is eluted between $78 \%$ and $69 \%$ in DOWEX 1X8 20-50 mesh and AMERLITE IRA 100 mesh, respectively, and remains adsorbed on DOWEX 1X8 200 mesh. It is known that radium $\left(\mathrm{Ra}^{2+}\right)$ does not form anionic chloride complexes. Therefore, it is not retained on strongly basic anion exchange resins in the whole range from 1 to $12 \mathrm{~N} \mathrm{HCl}$ concentrations $[16,18]$. However, the solubility of radium chloride decreases rapidly with increasing hydrochloric acid concentration; it can even precipitate in strong $\mathrm{HCl}$. Thus, the strong adsorption of Ra in the DOWEX 1X8 200 mesh can be stimulated by the large adsorption surface of this resin and the high concentration of $\mathrm{HCl}$. Therefore, the DOWEX $1 \times 8$ 20-50 mesh resin is recommended to separate $\mathrm{Ra}$ from $\mathrm{U}$.

Uranium (VI), lead (II), bismuth (III) and polonium
(IV) are retained in the resins.

\section{$3.2 \mathrm{At} 8 \mathrm{M} \mathrm{HCl}$}

Lead $\left(\mathrm{Pb}^{2+}\right)$ is not retained in the three anionic resins and is recovered more than $99 \%$ in the eluate. The $\mathrm{Pb}$ (II) species, $\mathrm{PbCl}^{+}$and $\mathrm{PbCl}_{2}$ predominate in 0.1-2 M HCl media, are only moderately adsorbed on Dowex ${ }^{\circledR} 1[16,18]$. The adsorption decreases linearly when increasing the acid concentration, because the anionic species present, $\mathrm{PbCl}_{3}{ }^{-}$predominant in 2- $4 \mathrm{M}$ $\mathrm{HCl}$ and $\mathrm{PbCl}_{4}{ }^{2-}$ in 4-12 $\mathrm{M} \mathrm{HCl}$, are weakly or not adsorbed in anionic resins.

Uranium (VI), bismuth (III) and polonium (IV) are retained in the resins.

\section{$3.3 \mathrm{At} \mathrm{H}_{2} \mathrm{O}$}

Uranium (VI) is not sorbed onto the anionic resins in $\mathrm{H}_{2} \mathrm{O}$ and therefore was eluted in the 3 anionic resins as cation species. Uranium (VI) exists as an uranyl ion, $\mathrm{UO}_{2}{ }^{2+}$, in aqueous solutions from $\mathrm{pH} 0.1$ up to 2 . Over that $\mathrm{pH}$, hydrolysis occurs and highly charged cation complexes are gradually formed before the hydroxide, $\mathrm{UO}_{2}(\mathrm{OH})_{2}$, precipitates. Uranium (VI) is sorbed onto the anionic resins in chloride solutions, because it forms anionic chloride species, such as $\mathrm{UO}_{2} \mathrm{Cl}^{+}$at $<0.3 \mathrm{M} \mathrm{HCl}, \mathrm{UO}_{2} \mathrm{Cl}_{2}$ between $0.3 \mathrm{M}$ and $0.9 \mathrm{M} \mathrm{HCl}$, $\mathrm{UO}_{2} \mathrm{Cl}_{3}{ }^{-}$at $>0.9 \mathrm{M} \mathrm{HCl}, \mathrm{UO}_{2} \mathrm{Cl}_{4}{ }^{2-}$ at $>3 \mathrm{M} \mathrm{HCl}$ and $\mathrm{UO}_{2} \mathrm{Cl}_{4}{ }^{2-}$ at $4 \mathrm{M}$ and $8 \mathrm{M} \mathrm{HCl}[16,19]$.

Bismuth (III) chloride is precipitated in the anionic resins as bismuth oxychloride when water is added as eluate, while polonium (IV), present in $\mathrm{HCl}$ solutions as a $\mathrm{PoOCl}_{4}{ }^{2-}$ ion, forms colloids, which are precipitated in the anionic resins [18].

In accordance with these results, uranium can be quantitatively separated from its descendants using anion-exchange resins, such as Dowex 1X8, 20-50 mesh (850-600 $\mu \mathrm{m})$ and Amerlite IRA, 100 mesh (150 $\mu \mathrm{m})$, only varying in $\mathrm{HCl}$ concentrations (Fig. 2).

The adsorption properties of Dowex $1 \mathrm{X} 8$ resin are modified by particle size (PZ). At 20-50 mesh 


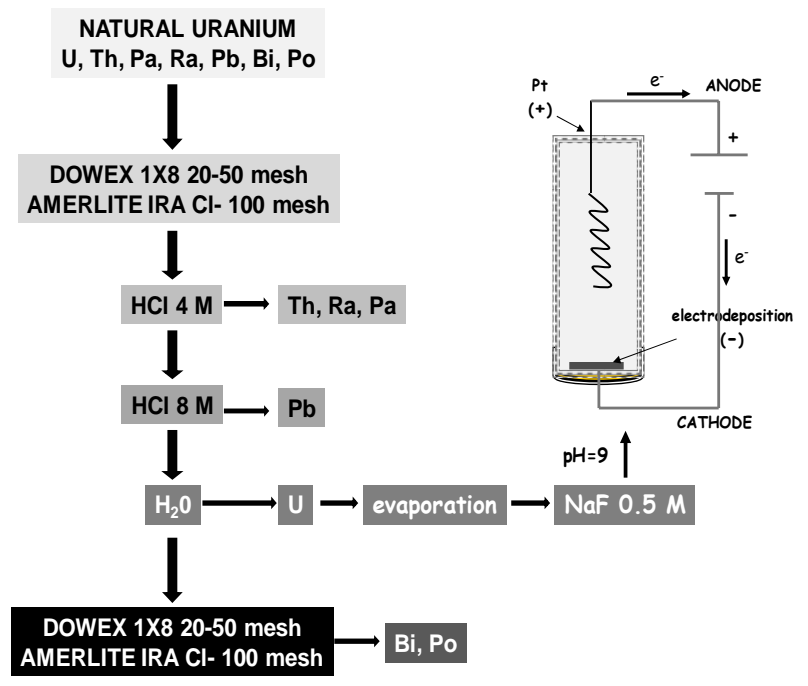

Fig. 2 Separation process of uranium from its radioactive descendants using DOWEX 1X8 20-50 mesh and AMERLITE IRA 100 mesh resins.

(850-600 $\mu \mathrm{m})$, Th and $\mathrm{Ra}$ are recovered at $4 \mathrm{M} \mathrm{HCl}$ and uranium is purified. However, at 200 mesh $(75 \mu \mathrm{m})$, radium is slightly adsorbed in $4 \mathrm{M} \mathrm{HCl}$; therefore, only a fraction is eluted at $4 \mathrm{M} \mathrm{HCl}$, and the rest is eluted when uranium is recovered with water. Ergo, a smaller anion resin $\mathrm{PZ}$ increases the adsorption properties of radium, causing the contamination of uranium with radium during its elution. An option to eliminate $\mathrm{Ra}$ from $\mathrm{U}$ would be eluted previously the chromatographic column with $1 \mathrm{M}$ or $2 \mathrm{M} \mathrm{HCl}$; uranium is adsorbed on the anionic column at this concentration of $\mathrm{HCl}$ after recovery of $\mathrm{Pb}(\mathrm{II})$, and $\mathrm{Ra}$ is eluted. Uranium can be finally recovered with water or a diluted $\mathrm{HCl}$ solution $(<0.01 \mathrm{M})$. However, this option involves an additional step in the separation process.

\subsection{Alpha Spectra}

The alpha spectra of purified uranium in each resin tested (see Fig. 3), show proof of the efficacy of the proposed separations. When uranium has not been purified, alpha spectrum shows a continuum from 3.5 $\mathrm{MeV}$ to $4.9 \mathrm{MeV}$, resulting from contributions of U-238, U-234, U-235, Th-230, and Ra-226, mainly (Fig. 3a). It is important to note that the rest of the alpha emitters generated in the uranium decay chains, whose alpha particle energies are greater than $5.3 \mathrm{MeV}$, such as Po-214 (7.6 MeV), Po-215 (7.3 MeV), Po-218 (6 MeV) or Bi-211 (6.6 MeV), do not appear in the alpha spectrum.

A good uranium purification is produced in the Dowex 1X8 20-50 mesh (850-600 $\mu \mathrm{m})$ and Amerlite $\AA$ IRA, 100 mesh $(150 \mu \mathrm{m})$ resins; in both cases, the peaks of U-238, U-234 and U-235 were well defined (Fig. 3c, Fig. 4d) while the alpha spectrum obtained in the Dowex 1X8 200 mesh resin is similar to unpurified uranium containing traces of Ra-223 and Th-227 (Fig. 3b).

It is known that the electrodeposition process of uranium involves the migration of uranyl ions $\left(\mathrm{UO}_{2}{ }^{2+}\right)$ to the cathode and the formation of insoluble uranyl hydroxide, which is absorbed on the cathode surface (Eq. (1)). Hydroxyl ions are formed by the reduction of water, which forms an infinitesimal layer on the cathode during the electrodeposition process (Eq. (2)) [13].

$$
\begin{gathered}
2 \mathrm{OH}^{-}+\mathrm{UO}_{2}^{2+} \leftrightarrow \mathrm{UO}_{2}(\mathrm{OH})_{2} \downarrow \\
2 \mathrm{H}_{2} \mathrm{O}+2 e^{-} \leftrightarrow 2 \mathrm{H}_{2}(g)+2 O \mathrm{H}^{-}
\end{gathered}
$$

\section{Conclusions}

Uranium can be quantitatively isolated from its descendants using Dowex 1X8 (20-50 mesh) or Amerlite IRA (100 mesh) resins, only varying in $\mathrm{HCl}$

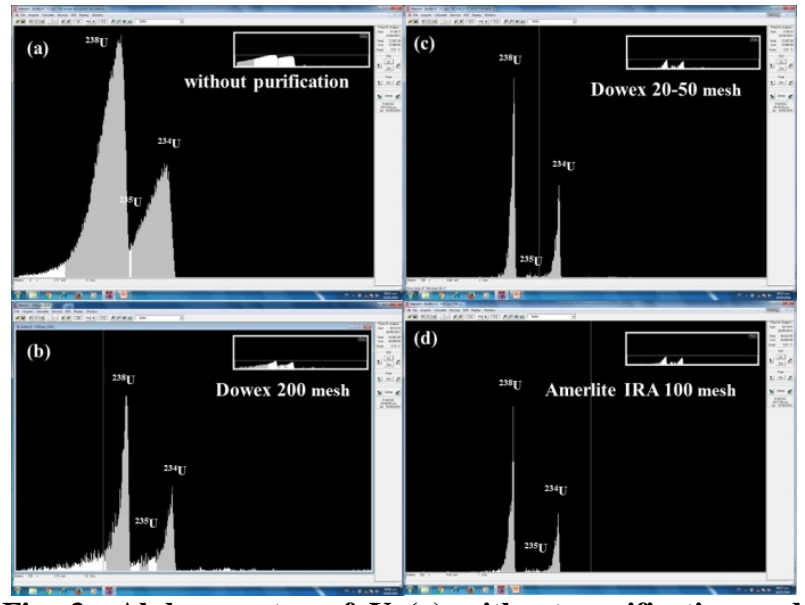

Fig. 3 Alpha spectra of $U$ (a) without purification and purified from its radioactive daughters with; (b) DOWEX $1 X 8200$ mesh; (c) DOWEX 1X8 20-50 mesh; and (d) AMERLITE IRA 100 mesh. 
concentrations. The methodology involves only 1 column packed with the anionic resin on which the uranium sample is added and eluted with 1) $4 \mathrm{M} \mathrm{HCl}$, to recover thorium, radium and protactinium; 2) $8 \mathrm{M}$ $\mathrm{HCl}$, to eluate lead; and 3) distilled water to recovered uranium. The process can be followed by gamma spectrometry and the purity of the uranium can be verified by alpha spectrometry.

The adsorption properties of radium in Dowex 1X8 resin are modified by $\mathrm{PZ}$ at high $\mathrm{HCl}$ concentrations, the smaller PZ of resin, the stronger the adsorption of radium into the resin.

\section{Acknowledgments}

This work was supported by CONACYT-SENER 212707 and ININ SR-501. The authors are indebted to Angel Jesus Juárez Neri who drawed the electrodeposition system, Ricardo Soria Juárez for providing the exchange resins and Dr. Eduardo Ordoñez for his technical advice.

\section{References}

[1] Boulyga, S. F., Testa, C., Desideri, D., and Becker, J. S. 2001. "Optimisation and Application of ICP-MS and Alpha-spectrometry for Determination of Isotopic Ratios of Depleted Uranium and Plutonium in Samples Collected in Kosovo." J. Anal. At Spectrom 16: 1283-9.

[2] Jia, G., Torri, G., and Innocenzi, P. 2004. "An Improved Method for the Determination of Uranium Isotopes in Environmental Samples by Alpha-spectrometry." J. Radioanaly Nucl Chem. 262: 433-41.

[3] Carvalho, F. P., and Oliveira, J. M. 2006. "Sequential Extraction Procedure for Determination of Uranium, Thorium, Radium, Lead and Polonium Radionuclides by Alpha Spectrometry in Environmental Samples." Czechoslovak J Phys. 56: D545-5.

[4] Ayranov, M., Krähenbühl, U., Sahli, H., Röllin, S., and Burger, M. 2005. "Determination of Neptunium in Soil by ICP-MS.” Radiochim Acta. 93: 249-57.

[5] Bourdon, B., Turner, S., Henderson, G. M., and Lundstrom, C. C. 2003. "Introduction to U-series Geochemistry." Rev. Miner Geochem. 52: 1-19.

[6] Korkisch, J. 1989. Handbook of Ion Exchange Resins:
Their Application to Inorganic Analytical Chemistry. Boca Raton, Florida, USA: CRC Press.

[7] Lehto, J., and Hou, X. 2011. Chemistry and Analysis of Radionuclides: Laboratory Techniques and Methodology. Weinheim, Germany : Wiley-VCH.

[8] Goldstein, S. J., and Stirling, C. H. 2003. "Techniques for Measuring Uranium-series Nuclides: 1992-2002.” Rev. Miner Geochem. 52: 23-57.

[9] Roberts, R. A., Choppin, G. R., and Wild, J. F. 1986. The Radiochemistry of Uranium, Neptunium and Plutonium-An updating. In: Nuclear Science Series: Radiochemistry of the Elements. NAS-NS-3063, DE86 007600. Technical Information Center Office of Scientific and Technical Information, United States Department of Energy, USA.

[10] Juntunen, P., Ruutu, A., and Suksi, J. 2001. "Determination of Ra-226 from Rock Samples Using LSC." In Proceedings of the International Conference on Advances in Liquid Scintillation Spectrometry, Karlsruhe, Germany, May 7-1: 299-302.

[11] Koornneef, J. M., Stracke, A., Aciego, S., Reubi, O., and Bourdon, B. 2010. "A New Method for U-Th-Pa-Ra Separation and Accurate Measurement of ${ }^{234} \mathrm{U}_{-}{ }^{230 \mathrm{Th}}{ }_{-}{ }^{231} \mathrm{~Pa}_{-}{ }^{226} \mathrm{Ra}$ Disequilibria in Volcanic Rocks by MC-ICPMS.” Chem. Geol. 277: 30-41.

[12] Alhassanieh, O., Abdul-Hadi, A., Ghafar, M., and Aba, A. 1999. "Separation of Th, U, Pa, Ra and Ac from Natural Uranium and Thorium Series." Appl Rad Isot. 51: 493-8.

[13] Crespo, M. T. 2012. "A Review of Electrodeposition Methods for the Preparation of Alpha-radiation Sources." App Rad Isot. 70: 210-15.

[14] Rožmarić, M., Ivšić, A. G., and Grahek, Ž. 2009. "Determination of Uranium and Thorium in Complex Samples using Chromatographic Separation, ICP-MS and Spectrophotometric Detection.” Talanta 80: 352-62.

[15] Ordoñez-Regil, E. 1986. "Preparación de Fuentes Finitas de Uranio Para la Espectroscopía." Alfa. Rev. Soc. Quim. Mex. 30: 84-6.

[16] Morss, L. R., Edelstein, N. M., and Fuger, J. 2010. The Chemistry of the Actinide and Transactinide Elements. 4th ed. Vol. 1. The Netherlands: Springer.

[17] Brown, D., and Gmelin, L. 1977. "Protactinium." In: Handbook of Inorganic and Organometallic Chemistry. Vol. 51. Heidelberg: Springer-Verlag.

[18] Lehto, J., and Hou, X. 2011. Chemistry and Analysis of Radionuclides: Laboratory Techniques and Methodology. Germany: Wiley VCH.

[19] Ahrland, S. 1949. "On the Complex Chemistry of the Uranyl Ion.” A. Chem. Scan. 374-400. 